Undas Vol 12. , Nomor 1, Juni 2016 : 91--98

\title{
ANALISIS KONFLIK SOSIAL DALAM CERPEN “KETIKA CINTA TAKDIRESTUI" KARYA TARJOYO (TINJAUAN SOSIOLOGI SASTRA)
}

\author{
Social Conflict Analysis in "Ketika Cinta Tak Direstui" Short Story \\ By Tarjoyono (Sociology of Literature Review)
}

\author{
YUTI MAHRITA
}

\author{
Balai Bahasa Kalimantan Selatan \\ Jalan Jenderal Ahmad Yani Km 32, 2, Loktabat, Banjarbaru 70712 Kalimantan Selatan \\ Telepon (0511) 4772641, Pos-el:
}

\begin{abstract}
Abstrak: Konflik merupakan pertentangan atau perbedaan antara dua orang atau kelompok. Konflik politik terbentuk karena adanya penguasa politik. Kekuasaan politik mempunyai cirriciri masyarakat secara keseluruhan sebagai objeknya. Konflik merupakan bagian kehidupan sosial, konflik sosial di latarbelakangi oleh perbedaan ciri-ciri yang dibawa individu dalam suatu interaksi. Konflik sosial yang terkandung dalam cerpen "Ketika Cinta Tak Direstui" karya Tarjoyo mengacu pada konflik eksternal khususnya pada konflik sosial. Mulanya konflik ini terjadi karena adanya pertentangan antara keluarga Risky yang kaya raya dan keluarga Nana yang miskin. Karena adanya perebedaan status sosial yang menghalangi cinta Nana dan risky yang membuat orang tua Risky tidak merestui Nana untuk mendampingi Risky. Metode yang digunakan dalam penelitian ini adalah metode deskriptif kualitatif. Data yang dihasilkan berupa kata-kata dalam bentuk kutipan-kutipan.
\end{abstract}

Kata kunci: Konflik, konflik sosial, sastra, masyarakat,kekuasaan.

Abstract: Conflict is dispute or contradiction between two or more people. Political conflict happened because there was political power. The character of political power is society as the object. Conflict is a part of social life which is happened because the difference of characters brought by individual when he/she has interaction. Social conflict in this short story "Ketika Cinta Tak Direstui" by Tarjoyo refers to external conflict especially social conflict. At first this conflict happens because there is contradiction of social status and social class between Rizky, the rich and Nana, the poor. Because of this status there is barrier between their love, Rizky and Nana, it makes Rizky's parent doesn't bless Nana to live with Rizky.This study uses qualitative descriptive method. The data are in the form of words and quotes.

Key words: Conflict, political and sosial conflict, literature, society, power.

\section{PENDAHULUAN}

Cerpen adalah cerita fiksi bentuk prosa yang singkat, padat, yang unsurunsur ceritanya terpusat pada satu peristiwa pokok sehingga jumlah dan pengembangan pelaku terbatas dan keseluruhan cerita memberikan kesan tunggal (Jabrohim, 1994:165-166).
Zaman sekarang banyak karya sastra baru yang telah lahir di kalangan masyarakat dan ditulis oleh sastrawansastrawan baru pula. Seiringnya dengan perkembangan zaman pada saat runtuhnya rezim orde baru tahun 1998 tidak hanya membawa kebebasan untuk bersuara, berpendapat dan berekspresi. 
Namun, juga turut mempengaruhi perkembangan sastra Indonesia.

Perkembangan itu ditandai dengan banyak bermunculan pengarang dan sastrawan baru yang kritis dan lugas dalam mengeluarkan karya-karya sastra yang bersifat eksperimental dengan menyuarakan kondisi-kondisi sosial yang selama ini menjadi hal tabu untuk dibicarakan atau diangkat sebagai karya sastra. Situasi dan kondisi itu tak lepas dari pasca reformasi 1998, juga pada munculnya para sastrawan, baik sastrawan yang sudah mempunyai nama maupun sastrawan baru memulai karir.

Kondisi itu dimanfaatkan betul untuk mengekspresikan karya-karya mereka yang terinspirasi dari kondisi sosial selama orde baru sampai akhir keruntuhannya. Mulai dari karya sastra yang menyuarakan tentang faktor sosial dan politik di masa orde baru, faktor pergantian generasi sastrawan juga turut mempengaruhi akan lahirnya para seniman dan sastrawan baru untuk berkreasi dan berkarya secara merdeka.

\section{KERANGKA TEORI}

\subsection{Cerpen}

Semi (1988:34) mengatakan bahwa "cerpen adalah penceritaan yang memusat pada satu peristiwa pokok sedangkan peristiwa pokok itu selalu tidak sendirian, ada peristiwa lain yang sifatnya mendukung peristiwa pokok". Menurut Edgar Allan Poe (dalam Nurgiantoro), seorang sastrawan kenamaan dari Amerika, cerpen adalah sebuah cerita yang dibaca dalam sekali duduk, kira-kira berkisar antara setengah sampai dua jam suatu hal yang kiranya tak mungkin dilakukan untuk sebuah novel. Panjang pendek ukuran cerpen tidak menjadi hal yang mutlak, tidak ditentukan bahwa cerpen harus sekian halaman atau sekian kata. Ada cerpen yang sangat pendek (short short story) berkisar 500-an kata, ada cerpen yang panjangnya sedang (midle short story), serta ada cerpen yang panjang (long short story) yang terdiri dari puluhan ribu kata (Nurgiyantoro, 2007:10). Sejalan dengan hal di atas Sudjiman,( 1984:15) mengatakan bahwa cerpen adalah kisahan pendek (kurang dari 10.000 kata) yang dimaksudnya memberikan kesan tunggal yang dominan; cerita pendek memusatkan diri pada suatu tokoh dalam suatu situasi pada suatu seketika. Meskipun prasyarat ini tidak terpenuhi, cerita pendek tetap memperlihatkan kepaduan sebagai patokan". Cerita pendek yang efekti berdiri dari tokoh atau sekelompk tokoh yang ditampilkan pada suatu latar dan latar belakang dan lewat lakuan lahir atau batin terlibat dalam suatu situasi. Tikaian dramatik, yaitu pembenturan antara kekuatan yang berlawanan merupakan inti cerita pendek.

Berdasarkan pendapat para ahli di atas dapat di simpulkan bahwa cerpen adalah sebuah karya sastra prosa naratif yang disajikan dalam satu peristiwa yang berkesan, singkat, padat, dan ide cerita berpusat pada satu tokoh serta dapat selesai dibaca dalam satu kali 
pembacaan. Cerpen diharapkan dapat memberikan kesan yang bermakna bagi pembacanya.

\subsection{Sosiologi Sastra}

Kritik sastra memiliki korelasi yang erat dengan perkembangan kesusastraan. Kritik sastra merupakan sumbangan yang dapat diberikan oleh para peneliti sastra bagi perkembangan dan pembinaan sastra untuk menentukan bagaimana sesungguhnya perkembangan kesusastraan dibutuhkan suatu kritik. Dalam penelitian ini, penulis menggunakan pendekatan sosiologi sastra untuk menganalisis cerpen "Ketika Cinta Tak Direstui" Karya Tarjoyo. Namun wilayah sosiologi sastra sangat luas. Wellek dan Warren (1993: 111) membagi telaah sosiologis menjadi tiga klasifikasi, yaitu: 1) sosiologi pengarang, yakni yang mempermasalahkan tentang status sosial, ideologi politik dan lain-lain, yang menyangkut diri pengarang; 2) sosiologi karya sastra, yakni yang mempermasalahkan tentang suatu karya sastra apa yang tersirat dalam suatu karya sastra dan tujuan atau amanat yang hendak ingin disampaikan; dan 3) Sosiologi sastra, yakni mempermasalahkan tentang pembaca dan pengaruh sosialnya terhadap masyarakat.

Eagleton (Wolfreys, 1999: 109) mengatakan bahwa "orang-orang berpendapat bahwateori marxis sebagai teori politik ketimbang teori sastra. Teori marxis diadopsi oleh banyak ilmu ditandai dengan tingginya tingkat perdebatan internal, meskipun terdapat perbedaan-perbedaan, tetapi teori tersebut tetap mempunyai tujuan bersama dan kominten yang sama". Hal ini merupakan keyakinan penganut aliran marsim tentang keterkaitan kata dan dunia, teori dan praktek dan ketidakadilan sistem kapasitas dalam berbagai bentuknya yang terlihat lebih mutakhir. Sehingga meskipun marxisme telah disebut oleh persepektif teoritis lainya, marxime adalah miskin sebagai teori tersebut telah menjadikan marxisme tidak populer, identifikasi yang dimana ahli teori semakin sedikit.

Williams (dalam Wolfreys, 1999: 116) menyatakan bahwa "kritik sastra Marxis lebih cenderung pada tekanan-tekanan dan kontradiksi di dalam karya sastra. Hal Ini sesuai sebab marxisme pada awalnya dirumuskan untuk menganalisis suatu tekanan dan pertentangan di dalam masyarakat". Kritik sastra Marxis juga memandang literatur sangat dekat terhubung dengan kekuatan sosial dan analisis mereka atas literatur yang berhubungan dengan pertanyaan-pertanyaan sosial paling besar. Sejak marxisme sebagai sistem kepercayaan yang dapat digunakan untuk analisa masyarakat pada tingkat level paling besar dan terperinci, Kritik sastra Marxis sejatinya adalah bagian dari upaya dan usaha besar untuk membongkar bagian dalm masyarakat.

\subsection{Konflik dalam cerpen}

Konflik adalah sesuatu yang dramatik, mengacu pada 
pertarungan antara dua kekuatan yang seimbang dan menyiratkan adanya aksi dan aksi balasan. "konflik adalah sesuatu yang 'dramatik', mengacu pada pertarungan antara dua kekuatan yang seimbang, menyiratkan adanya aksi dan aksi balasan". Dengan demikian konflik ialah sesuatu yang tidak menyenangkan dan menyebabkan suatu aksi dan reaksi dari hal yang dipertentangkan tokoh dalam suatu peristiwa (Wellek \& Warren, 1989: 285). Dua kelas ini satu sama lain tidak bisa saling menyesuaikan kehendak, usaha dan maksudmaksudnya. Kelas buruh berusaha untuk mencukupi kehidupan diri dan keluarganya, berikhtiar supaya mendapatkan pekerjaan yang layak. Tetapi kelas majikan berusaha mencari keuntungan dari perusahaannya (perkebunan)dan mereka akan mendapat untung bila orang-orang yang menjadi buruhnya bisa memberi keuntungan, misalnya mereka senang (buruh) mendapat upah rendah, suka bekerja berat, dan sebagainya. Dalam suatu kehidupan sosial, manusia tidak dapat melepaskan ekspresinya dari jalinan hubungan manusia lain. Suatu struktur sosial yang dibentuk oleh kelompok masyarakat tertentu akan memberlakukan satu nilai sosial tertentu pula. Adanya perbedaan kepentingan antar individu yang menghuni suatu masyarakat akan menimbulkan bentrokan atau konflik.

\subsection{Macam-macam Konflik}

Stanton (dalam Nurgiyantoro, 2002:124) menyatakan bahwa konflik dibedakan menjadi dua kategori, yaitu konflik internal dan eksternal. Konflik internal atau kejiwaan adalah konflik yang terjadi dalam hati jiwa seorang tokoh cerita. Jadi, konflik ini adalah konflik yang dialami manusia dengan dirinya sendiri, sedangkan konflik eksternal adalah konflik yang terjadi antara seorang tokoh dengan sesuatu dengan di luar dirinya. Konflik eksternal ini dibedakan dalam dua kategori lagi oleh Jones (1968:30), yaitu 1) konflik fisik dan 2) konflik sosial. 1) Konflik fisik adalah konflik yang disebabkan oleh adanya perbenturan antara tokoh dengan lingkungan alam; dan 2) Konflik sosial adalah konflik yang disebabkan oleh adanya kontak sosial atau masalah-masalah yang muncul akibat adanya hubungan antar manusia.

\section{METODE PENELITIAN}

Metode yang digunakan dalam penelitian ini adalah metode diskriptif kualitatif. Data yang dihasilkan berupa kata-kat dalam bentuk kutipan-kutipan. Data diperoleh dari paparan teks yang menjelaskan konflik politik dan sosial dalam bentuk dialog, monolog, dan narasi. Sebagai instrument pembantu pengumpulan data, dibuat tabel kodofikasi data sebagai cara untuk mempermudah analisis data. Pendekatan sosialogi sastra yang difokuskan pada sosiaologi karya dimanfaatkan untuk membantu 
menafsirkan makna yang terdapat dalam cerpen dan memahami latar sosial kehidupan dalam cerpen. Hasil yang diperoleh dari penelitian ini adalah deskripsi konflik yang terjadi dalam cerpen "Ketika Cinta Tak Direstui" karyabTarjoyo.

Hasil penelitian dapat disarankan kepada beberapa pihak, yaitu (1) bagi penelitian lanjutan dapat menggali lebih dalam makna yang tersirat dalam cerpen "Ketika Cinta Tak Direstui" karya Tarjoyo melalui pendekatan yang berbeda (2) bagi pembaca agar dapat memanfaatkan hasil penelitian untuk menghayati lebih dalam konflik yang terjadi dalam interaksi kehidupan masyarakat.

\section{ANALISIS DAN PEMBAHASAN}

\subsection{Konflik Eksternal dalam cerpen}

Konflik sosial yang terkadung dalam cerpen "Ketika Cinta Tak Direstui" karya Tarjoyo mengacu pada konflik eksternal khususnya pada konflik sosial. Mulanya konflik ini terjadi karena adanya pertentangan antara status sosial atau kelas sosial antara keluarga Risky yang kaya raya dan keluarga Nana yang miskin. Karena adanya status sosial tersebutlah yang menghalang cinta Nana dan Risky yang membuat orang tua Risky tidak merestui Nana untuk mendampingi Risky.

"aku gak bisa dihina kayak gini Ky, aku memang miskin tapi aku punya harga diri. Kita itu banyak pebedaan, aku memang orang gak mampu tapi sumpah demi Allah, aku gak pernah pelet kamu, .... aku tulus sayang sama kau" jawab ku dengan nada tersedu-sedu karena menangis, selama ni aku selalu ngasih motivasi untuk kamu, nyuruh kamu terus sekolah, tapi apa? mereka tetap menyalah kan ku. Kejadian malam tadi, membuat aku takut menemuinya. Kucoba menghindar,namun apalah kekuatan cinta itu tak mampu pisah kan kami. Tuhan, terima kasih udah takdirkan dia untuk ku, meski cinta kami tak dapat restu, tapi aku yakin, harta mereka tak'an mampu membuat dia dan aku bahagia. (Tarjoyo,2012:7)

Berdasarkan kutipan di atas terlihat jelas dengan yang disebut Marx sebagai pertentangan kelas, antara kelas orang yang berada (kaya) dengan orang yang tidak berada (miskin). akibat dari faktor hubungan-hubungan ekonomi yang timpang, pada akhirnya menimbulkan pertentangan kelas yang menjadi penghalang antara hubungan Nana dan Risky. Kutipan berikut menunjukan gejala itu.

Konflik politik yang terkadung dalam cerpen "Ketika Cinta Tak Direstui" karya Tarjoyo adalah pertentangan antara cinta Nana dan Risky yang ditentang oleh orang tua Risky. Pada waktu itu ibu Risky membawa Nana menuju ke kantornya dan disepanjang jalan ibu Risky berbicara dengan sopan dan lembut. Namun, dibalik kelembutannya itu ada tujuan lain. Kelembutan ibu Risky itu dapat dikatakan hanya sebagai teknik atau strategi agar aku mau diajaknya ke kantor dan mengatakan ingin menyelesaikan masalah Risky. Konflik ini terjadi pada saat kakak Risky menanyakan apa yang Risky lakukan kalau Nana tidak lagi bersamanya dan 
dengan singkatnya Risky pun menjawab "mati". Mendengar hal demikian tibatiba saja ibu Risky datang dan memfitnah Nana telah mengguna-gunai anaknya Risky, seperti kutipan di bawah ini.

Tiba-tiba, suara seorang ibu terdengar dan berkata "kamu, pelet anak saya?" pertanyaan itu, begitu mencambuk ku. Terlintas wajah papa difikiran ku saat itu, aku ingat perjuangannya membesarkanku dengan ilmu-ilmu agama, tak pernah papa mengajarkan ku aliran sesat sedikit pun. Air mata ini terasa ingin menetes. Riski membatah pertanyaan ibunya, "mama, jangan kayak gitu lah"! mama nya terus mengujamku dengan sebuah pertanyaan, yang menusuk, mereka menanyakan apa pekerjaan orang tua ku! dan aku menjawab "ibu saya seorang ibu rumah tangga, dan papa saya bekerja sebagai cleaning service disebuah hotel."

"Emang cukup, untuk hidup kalian tuh"? pertanyaan itu benarbenar membuat aku tak punya harga diri. Akhirnya, pertemuan singkat itu selesai, Riski mengajak $\mathrm{ku}$ masuk dalam mobil, dan bicara padaku empat mata,(Tarjoyo, 2012: 7)

Berdasarkan kutipan di atas terlihat jelas bahwa kata manis yang lontarkan ibu Risky hanyalah bagian dari politiknya saja agar ia bisa mempermalukan Nana di hadapan seluruh kelurga. Kalimat-kalimat kasar dan hinaan yang dilontarkan oleh ibu Risky membuat Nana merasa terpukul dan merasa tidak dihargai sama sekali. Awalnya Nana mengira keluarga Risky bisa menerimanya tetapi pada kenyataannya setelah Nana di bawa kehadapan semua keluarga Risky ternyata Nana malah mendapatkan fitna dan hinaan. Hal ini menunjukkan bahwa kelas sosial ataran Nana dan Risky telah menjadi penghalang dalam cinta mereka berdua.

\subsection{Konflik Internal Tokoh (Nana)}

Konflik yang dialami toko Nana dalam cerpen "Ketika Cinta Tak Direstui" karya Tarjoyo adalah ketika ia ditinggal kekasihnya Risky untuk sekolah ke Sorek. Pada waktu itu Risky menyampaikan kepada Nana bahwa ia akan pindah sekolah ke Sorek. Hal ini membuat Nana begitu tertekan karena ia akan berpisah dengan orang yang ia sayangi seperti kutipan di bawah ini.

"ada yang mau aku bilang sama kamu, Na!"

"apa bilang lagi" aku tersenyum.

"aku dipindahkan sekolah sama mama aku, ke Sorek kampung aku"!

"hahaha, aku tertawa menatapnya, kamu becanda kan?

"aku serius!" jawab Risky.

Tertawaku menjadi sebuah bencana yang terasa mencambuk, air mata terasa ingin menetes, ketika pengakuan darinya bukan sebuah lelucon, tapi aku coba tenangkan diri aku dan keadian itu hanya sebuah mimipi, namun apa daya itu semua nyata. Waktu terus berputar, hingga menunjukan waktu 19.15. Malam minggu ini terasa sangat biasa saja, tak ada kebahagian dari raut wajahku setelah mendengar cerita siang tadi, karena malam ini adalah malam terakhir aku bersamanya, (Tarjoyo, 2012: 2). 
Berdasarkan kutipan di atas menunjukkan bahwa tokoh si aku telah mengalami berbagai macam konflik dengan perasaannya karena ditinggal jauh oleh orang yang ia sayangi.

Konflik lain yang selalu dirasakan oleh tokoh Nana adalah selalu dihantui oleh rasa takut akan hubungannya dan Risky. Nana merasa kalau keluarga Risky tidak akan merestui hubungan mereka berdua. Namun, Risky selalu berhasil meyakinkan Nana akan cintanya kepada Nana sehingga Nana pun merasakan kedamaian mendengar perkataan Risky seperti kutipan di bawah ini.

"Ky, aku takut kalau orang tua kamu gak merestui hubungan kita!" "Kamu tenang ajalah, yang jalani kan aku bukan mereka" dia terus coba untuk meyakinkan ku!"

"Aku hanya menarik nafas dan tersenyum padanya!", ( Tarjoyo, 2012: 1 ).

Konflik demi konflik yang dirasakan Nana. Dalam kondisi inilah Nana mengalami konflik batin dalam hatinya. Dari kutipan dan pemaparan di atas, konflik yang dialami Nana bukan hanya konflik eksternal saja namun konflik internal atau batinnya sehingga rasa takut itu membuatnya selalu merasa dihantui.

\section{PENUTUP}

Seperti yang sudah dijelaskan pada pembahasan sebelumnya, rangkaian analisis ini bertujuan untuk mengetahui konfik sosial dan politik yang terjadi dalam cerpen "Ketika Cinta Tak Direstui" karya Tarjoyo. Cerpen "Ketika Cinta Tak Direstui" adalah satu di antara sekian cerita tentang perbedaaan sosial, yaitu yang kaya dan yang miskin sehinggan munculnya sebuah konflik. Ditinjau dari teori Marx bahwa yang menjadi konflik sosial dalam cerpen di atas adalah konflik eksternal khususnya pada konflik sosial dan politik. Konflik sosial dalan cerpen "Ketika Cinta Tak Direstui" terjadi karena adanya pertentangan antara status sosial atau kelas sosial antara keluarga Risky dan Nana atau si kaya dan si miskin, sedangkan pada bagian politik muncul dengan menggunakan salah satu strategi untuk menghina Nana. Selain konflik ekternal juga terdapat konflik batin yang dialami tokoh Nana adalah rasa sepi yang dirasakan Nana ketika ditinggalkan kekasihnya dan rasa takut akan hubungan cintanya yang tak direstui oleh keluarga Risky. Jadi, dapat dikatan bahwa teori Marx dalam cerpen di atas lebih menonjol pada perbedaan kelas atau status sosial antara orang yang kaya dan orang yang miskin.

\section{DAFTAR PUSTAKA}

Jabrohim (Ed). 1994. Pengajaran Sastra. Yogyakarta: Pustaka Pelajar.

Jones, A. J.1986. Prinsiple of Guidence. New York: McGraw Hill Book Company Inc. 
Jonson. Doyle Paul. 1986. Teori Sosiologi Klasik dan Modern. Terjemahan Robert M.Z. Lawang Jakarta: PT. Gramedia Pustaka Utama.

Luxemburg, Jan Van, dkk. 1986. Pengantar Ilmu Sastra. Terjemah Dick Hartono. Jakarta: Gramedia.

Nurgiyantoro. Burhan. 2007. Teori Pengkajian Fiksi. Yogyakarta: Gadjah Mada Universty Press.

Semi, M. Atar. 1988. Anatomi Sastra. Padang: Angkasa Raya.

Wellek, Renne \& Austin Warren. 1989. Teori Kesusastraan. Jakarta: Gramedia Pustaka. Gramedia Pustaka. 1993. Teori Kesusastraan. Terjemahan Melani Budianto. Jakarta: PT.

Wolfreys, Julian. 1999. Literary Teories.New York: University Press. 